\title{
THE GUEST ANT, SYMMYRMICA CHAMBERLINI, REDISCOVERED NEAR SALT LAKE CITY, UTAH (HYMENOPTERA, FOR MICIDAE)*
}

\author{
By Alfred Buschinger ${ }^{1}$ ANd Andre Francoeur ${ }^{2}$
}

\section{INTRODUCTION}

In a series of recent papers we investigated the social structures of Formicoxenus nitidulus, F. hirticornis, and Leptothorax provancheri (Buschinger und Winter 1976, Buschinger 1979, Buschinger, Francoeur and Fischer 1980). They are all so-called guest ants, small species living in independent colonies within the larger nests of their host species. Formicoxenus gains its food by soliciting it from the Formica hosts, or by stealing food when two Formica workers feed each other (Stäger 1925, Buschinger 1976). L. provancheri are often seen licking the head and body of their Myrmica hosts; however, it remains uncertain how they really get their food. Our observations revealed that these guest ants had some interesting features in common, such as a functional monogyny, a queen polymorphism with dealate and intermorphic females, and a tendency to mate within or on the upper surface of the host nest. The Formicoxenus species recognized up to now have wingless, workerlike males, whereas the L. provancheri male exhibits an ordinary winged shape.

It was a challenging task, therefore, to search for Symmyrmica chamberlini Wheeler (1904), another guest ant with wingless males and living together with Manica mutica, in order to study its biology and to find out its relationship to the species mentioned above. We took the opportunity of visiting the type area of $S$. chamberlini in the vicinity of Salt Lake City, Utah, after the 9th Congress of IUSSI in Boulder, Colorado. We were able to rediscover this ant and to collect some new material which yielded additional support for an incorporation of Symmyrmica into Formicoxenus.

\footnotetext{
'Fachbereich Biologie, Institut für Zoologie, der Technischen Hochschule, Schnittspahnstr. 3, D 6100 Darmstadt, FRG

${ }_{2}^{2}$ Département des sciences fondamentales, Université du Québec à Chicoutimi, Chicoutimi, Québec, Canada G7H 2B1

*Manuscript received by the editor April 3, 1983.
} 


\section{Field Observations and Collecting Site}

The original description of Wheeler (1904) indicates the type locality only inaccurately as "near Salt Lake City, Utah, in the flood-plains of Jordan River", where the host species, Manica mut$i c a$, was said to be common in some localities. S. chamberlini, however, was found only in one particular ten-acre field and, despite an intensive search, in no other locality. Unfortunately Wheeler's paper (1904) contains no further details on the exact site of that field.

On August 15, 16 and 17, 1982 we located about 30 flourishing Manica mutica populations along the Jordan River, beginning with our search near Lehi and working down the river to North Salt Lake. We followed the roads and highways crossing the river, and, always beginning at the bridges, we looked for the host species in or near the banks. M. mutica was found near Lehi, on the eastern bank north of the bridge of road no. 73, and in several places in West Jordan (between 5400 South Street and 7800 South Street, east bank), in Murray and South Salt Lake (between 5300 and 3300 South Street). Often the colonies seemed loosely concentrated. A search in Big Cottonwood Canyon was not successful. We have heard since then that unfortunately, late in following September, the Jordan River heavily flooded the type area, the only known nesting site for $S$. chamberlini.

The species was detected only in one locality, on the eastern bank of the river, about $200 \mathrm{~m}$ south of the bridge of 3300 South Street, South Salt Lake. Manica mutica there forms large nests in the silty soil just in the upper edge of the steep river-bank about $2 \mathrm{~m}$ above the waterline. The area is a horse pasture with poor, short vegetation, which was quite dry in August. Between two nests containing chamberlini there was a willow brush, and in the estate adjoining to the north, some rose bushes covered partly a private garbage dump. One very large mutica colony with a chamberlini nest was found there underneath a piece of concrete $(50 \times 18 \times 15 \mathrm{~cm})$.

Altogether we found chamberlini in three mutica nesting sites, with distances of about $6 \mathrm{~m}$ between one other. We could not decide whether the flourishing mutica nests belonged to separate colonies, or whether they were parts of a large supercolony. However, two samples of living workers from two similarly adjacent nest sites of another locality (3900 South Street, South Salt Lake City) were successfully mixed and became host of chamberlini colony no. 3 . 
Single mutica workers or groups with and without brood were found nearly everywhere in that area when we dug a few centimeters into the soil.

The first site, the southernmost one (Fig. 1), yielded just 30 chamberlini workers and intermorphs, but no brood (colony no. 1 in the following). In the second site, about $6 \mathrm{~m}$ to the north and beyond the willow brush, we found a chamberlini nest (no. 2) about $15 \mathrm{~cm}$ below the surface, in the soil and surrounded by larger tunnels with mutica workers and brood. The chamberlini nest contained larvae and prepupae, about 38 workers and intermorphs, two wingless males, and one male pupa. The prepupae from this colony were used for a karyotype study. In the third site, again about $6 \mathrm{~m}$ to the north, in the garbage dump, we found a chamberlini nest (no. 3) with about 30 workers and intermorphs, pupae, prepupae, and larvae. One dealate female was detected but escaped capture. The relative importance of intermorphs for our samples is given in table 1 in comparison with Wheeler's data.

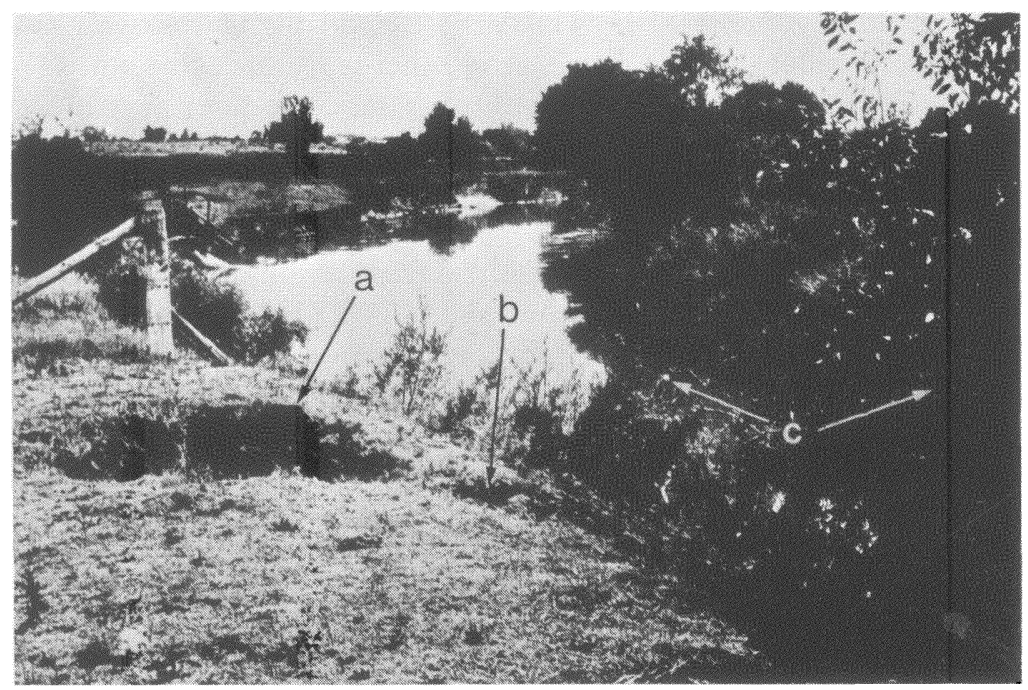

Fig. 1. The chamberlini site on the east bank of Jordan River, looking southward (upriver).

a) Site of chamberlini colony no. 1 within a Manica colony

b) Site of another Manica colony which extended along the willow brush to the right

c) willow brush between chamberlini colonies 1 and 2 


\section{RESUlTS OF DISSECTING SYMMYRMICA CHAMBERLINI}

The three samples were kept alive for several months. However, numerous specimens died during the first few weeks. A number of them could be dissected following the method described by Buschinger and Alloway (1978).

In a total of 15 ordinary workers without any vestiges of ocelli on their heads, the number of ovarioles was always two, except in one specimen which has three. No spermatheca could be found in any of these workers.

On the contrary, we found five slightly intermorphic specimens, with between one and three more or less perceptible ocelli, with somewhat deeper thoracic sutures, and with 6 ovarioles and a spermatheca each. Two of these specimens, both from colony no. 2 (where males had been present), contained living sperm in their receptacles. Their ovarioles, however, were short and transparent as is usual in young, not yet egg-laying females.

Additional observations were made referring to the abdominal glands of $S$. chamberlini. Thus, the poison gland reservoir was always of usual size and shape, as in other leptothoracine ants. The Dufour's gland, however, is large both in workers and intermorphic females. Its size exceeds considerably that of independent Leptothorax species, and it reaches that of, e.g., Harpagoxenus sublaevis (Buschinger and Alloway 1978).

A karyological study of 7 prepupae from colony no. 2 was made following the method of Imai et al. (1977). The results, however, were not as good as to permit the presentation of a karyotype. We could only determine the chromosome number, which is $2 n=28$.

\section{LABORATORY OBSERVATIONS}

We were not able to take large samples of the Manica host species with us alive. So only very few observations of interactions between chamberlini and their hosts were possible. However, following a method which had already worked with Formicoxenus nitidulus (Buschinger 1976), we tried to join chamberlini brood and adults with an unnatural host species. We chose a Leptothorax species which was nesting within dead willow stems near to our chamberlini site. Apparently it represents an unknown, new species belonging to the subgenus Leptothorax (= Mychothorax Ruzsky). The following experiments and observations were made: 
a) After an artificial wintering, four $S$. chamberlini specimens of colony no. 3 were isolated with 5 pupae of the Leptothorax species. Honey and freshly killed Drosophila were provided. However, the chamberlini did not survive. Two agonizing chamberlini, almost without movement, were returned to the Manica mutica artificial nest arena. The Manica workers immediately brought them into the nest, and licked them all over. A few hours later, the two chamberlini could feebly walk. Next day, they were running normally in the nest and its arena, having completely recovered. When an apparently dead chamberlini was offered to mutica workers, they put it in the refuse heap confirming its death. Trophallactic exchange between chamberlini nestmates was never seen, but only one was noted between chamberlini and mutica.

b) The larvae and pupae of colonies no. 2 and 3 were put into a nest together with 20 workers of the Leptothorax species mentioned above. One chamberlini worker hatched, but died (or was killed?) after two weeks. Chamberlini larvae survived an artificial hibernation from 27 October to 1st December 1982. They were easily distinguished from the Leptothorax larvae which developed from workerlaid eggs: the chamberlini larvae are much hairier.

After the hibernation, the colony raised numerous alate Leptothorax males, but no chamberlini. The chamberlini larvae vanished one after the other.

c) About 20 workers and intermorphs of colony no. 2 were placed together with 25 white and brown worker pupae and a few larvae of the Leptothorax species on 1st September, 1982. After one week, the first Leptothorax workers had hatched, and 12 chamberlini were still alive. Among them an intermorph which had lost the right antenna seemed to become fertile. This specimen, later on, was observed several times to lay an egg. Together with a second intermorph it was still alive on 12 April, 1983.

The first, comparatively long-shaped eggs of chamberlini appeared three weeks after the beginning of the experiment. Adult chamberlini often fought with each other, possibly in order to eliminate supernumerary reproductives. Some of the victims of these fights were dissected, when they were not too much decomposed. In addition, not only inseminated intermorphs but also ordinary workers died rapidly. After the hibernation (cf. section b), only two chamberlini intermorphs were alive, among them the one with only 
the left antenna. Both became fertile again, and the brood still contained some hairy chamberlini larvae. Between 15 December and 26 January, in a temperature rhythm of 12 hours $/ 15^{\circ} \mathrm{C}$ and 12 hours/ $25^{\circ} \mathrm{C}$, several Leptothorax males, females and workers hatched, but no chamberlini larva reached the pupal instar.

After raising the temperature to $10 \mathrm{~h} / 17^{\circ} \mathrm{C}$ and $14 \mathrm{~h} / 28^{\circ} \mathrm{C}$ on 2 nd February, 1983, three chamberlini larvae became prepupae, and on 10 and 12 March two prepupae molted into apterous male pupae. Nevertheless, it is doubtful whether breeding of chamberlini with that Leptothorax will be as successful as the experiments with Formicoxenus nitidulus and Leptothorax acervorum as host species (Buschinger 1976), since both pupae and the remaining prepupa were eaten during the following three days. In the mixed colony chamberlini/Leptothorax sp. we observed quite amicable relations between the two species. Often the chamberlini solicited food from Leptothorax workers, and sometimes they were seen licking the mouthparts of larvae. We never saw a chamberlini foraging outside the nest, where honey and pieces of Tenebrio or Periplaneta were offered as food. The chamberlini larvae, like those of the Leptothorax species, are fed with solid particles of the insect pieces. Leptothorax workers place the particles on the ventral surface of the larvae, which then chew and eat them.

\section{Discussion}

Our knowledge of the biology of this rare ant still remains fragmentary. We can confirm the observation of Chamberlin, as reported by Wheeler (1904) in that we also found this ant in mixed colonies with Manica mutica, in the flood-plains of Jordan River near Salt Lake City. The guest ants are living within independent nests in the midst of prosperous Manica colonies. However, we could not observe whether they solicit food from their hosts, or what are the other relations of the two species. The observation mentioned in the previous section, experiment a, raises questions of whether the licking of chamberlini by the mutica hosts is linked to any important cuticular secretion.

The nesting habits of $S$. chamberlini resemble closely those of Leptothorax provancheri, the guest ant of Myrmica incompleta Provancher (Buschinger et al. 1980). As was already suggested by 
Table 1. Ratios of workers and intermorphs in colonies of Symmyrmica chamberlini

\begin{tabular}{lccc}
\hline Source & Workers (\%) & Intermorphs (\%) & Total \\
\hline Wheeler (1904) & $8(38)$ & $13(62)$ & 21 \\
Colony no. 1 & $20(66)$ & $10(33)$ & 30 \\
Colony no. 2 & $16(42)$ & $22(58)$ & 38 \\
Colony no. 3 & $13(43)$ & $17(57)$ & 30 \\
\hline$\Sigma$ & $57(48)$ & $62(52)$ & 119 \\
\hline
\end{tabular}

Wheeler (1910), S. chamberlini is closely allied to the genus Formicoxenus, guest ants of Formica species in Europe and North America. Since the wingless male of chamberlini nevertheless is not as workerlike as the Formicoxenus male, Wheeler may be right in suggesting that it could represent an archaic form of Formicoxenus.

The close relationship of $S$. chamberlini and Formicoxenus is further corroborated by our observations of intermorphic queens in our new material. Such queens, which often look like ordinary workers except that they have one or up to three vestigial ocelli and sometimes a little bit more developed thoracic sutures, occur quite frequently in Formicoxenus nitidulus (Buschinger and Winter, 1976), in F. hirticornis (Buschinger, 1979), and in Leptothorax provancheri (Buschinger et al. 1980). We cannot yet determine whether $S$. chamberlini also has a functional monogyny like the 3 guest ants we mentioned above. This would mean that alongside one functional queen in each nest, there exists one or several inseminated but not egg-laying potential queens. However, at least our finding of two recently inseminated intermorphic females in $S$. chamberlini colony no. 2 reveals that, as in the other guest ants, copulation takes place within or near the mother colony, and that newly mated females may remain for a while in the mother nest.

The analysis of intermorph composition presented in table 2 based on the classification of Plateaux (1970) for caste polymorphism in Leptothorax nylanderi, revealed only few superior intermorphs with intermediate trunk between a fully developed gynomorph and a typical ergatomorph. Moreover the inferior intermorph classes seem to be dominated by the form 4 which has 3 small or minute ocelli in any combination, a mesothorax not, or slightly enlarged, a promesonotal suture more or less prominent. The individuals with a potential or actual queen function capacity are found 
Table 2. Types of $S$. chamberlini intermorphs according to Plateaux' classification of Leptothorax nylanderi.

\begin{tabular}{lccccc}
\hline Source & Form 2 & Form 3 & Form 4 & Form 6-7 & Total examined \\
\hline Wheeler (1904) & 0 & 1 & 5 & 0 & 6 \\
Colony no. 1 & 3 & 1 & 4 & $\left.2^{+}\right)$ & 10 \\
Colony no. 2 & 7 & 0 & 13 & $\left.2^{++}\right)$ & 22 \\
Colony no. 3 & 2 & 2 & 13 & 0 & 17 \\
\hline
\end{tabular}

+) Both with thoracic sutures and sclerites according to Plateaux' form 7, except for the lack of wings. One specimen with very short forewing rudiments.

${ }^{+}$)Two specimens between Plateaux' form 6 and 7, without traces of wings.

mainly in that class of intermorphs. It is worthy to stress that Holliday's (1903) data for 1000 specimens of $L$. provancheri includes $37 \%$ of intermorphs without the microgynes; the intermorph composition exhibits the same trends as in chamberlini.

The karyotypes cannot yet confirm a closer relationship of all these guest ants. However, they also do not contradict such an assumption. $F$. nitidulus has a haploid number of $\mathrm{n}=15$ chromosomes, $L$. provancheri has $\mathrm{n}=11$, and $S$. chamberlini with $\mathrm{n}=14$ lies in between. For F. hirticornis and diversipilosus the chromosome numbers are not yet known.

Summing up the known features, queen polymorphism with alate and intermorphic females, males with their tendency to reduce wings and to become ergatomorphic, the presence of inseminated young (and in Formicoxenus also old) potential queens in the nests, and the life habits as guest ants, we believe that Symmyrmica, and also $L$. provancheri, should be incorporated in the genus Formicoxenus. A comparative morphological study has been undertaken in order to link the biological informations accumulated on the guest ants mentioned above in a taxonomic revision of the genus Formicoxenus.

\section{ACKNOWLEDGEMENTS}

We thank Karl Fischer for providing the chromosome number of Symmyrmica chamberlini, and Robert Loiselle for laboratory assistance. Wheeler's specimens were loaned by the American Museum of Natural History, New York (Mrs. A. Favreau), and by the USNM, Washington, through Dr. D.R. Smith (USDA). 
The field work was supported by a grant of the Deutsche Forschungsgemeinschaft (Buschinger) and a grant of the Natural Science and Engineering Research Council of Canada (Francoeur).

\section{SuMMARY}

Symmyrmica chamberlini was described by Wheeler (1904) from specimens taken by C.V. Chamberlin in 1902 in a colony of Manica mutica (Emery) near Salt Lake City. No further records of this species are known. In order to find out the systematic relations of Symmyrmica to other ants like Leptothorax provancheri Emery or those of the genus Formicoxenus, we have collected some new material in August 1982, in the Salt Lake City area. The morphology, female polymorphism, and wingless male together with biological features indicate that $S$. chamberlini is a species that should belong to the genus Formicoxenus.

\section{REFERENCES}

Buschinger, A. (1976): Eine Methode zur Zucht der Gastameise Formicoxenus nitidulus (Nyl.) mit Leptothorax acervorum (Fabr.) als "Wirtsameise" (Hym., Form). Ins. soc. 23, 205-214.

BusChinger, A. (1979): Functional monogyny in the American guest ant Formicoxenus hirticornis (Emery) (= Leptothorax hirticornis), (Hym., Form.). Ins. soc. 26, 61-68.

Buschinger, A. ANd Alloway, T. M. (1978): Caste polymorphism in Harpagoxenus canadensis M. R. Smith (Hym., Formicidae). Ins. soc. 25, 339-350.

Buschinger, A., Francoeur, A. AND Fischer, K. (1980): Functional monogyny, sexual behavior, and karyotype of the guest ant, Leptothorax provancheri Emery (Hymenoptera, Formicidae). Psyche 87, 1-12.

Buschinger, A. UND WinTer, U. (1976): Funktionelle Monogynie bei der Gastameise Formicoxenus nitidulus (Nyl.) (Hym., Form.). Ins. soc. 23, 549-558.

HollidaY, M. (1903): A study of some ergatogynic ants. Zool. Jb. Syst. Okol. Geogr. Tiere 19: 293-328.

Imai, H. T., Crozier, R. H. ANd TAylor, R. W. (1977): Karyotype evolution in Australian ants. Chromosoma 59, 341-393.

Plateaux, L. (1970): Sur le polymorphisme social de la fourmi Leptothorax nylanderi (Foerster). 1. Morphologie et biologie comparées des castes. Ann. Sci. Nat. Zool. 12e S., 12, 373-478.

STÄGER, R. (1925): Das Leben der Gastemeise (Formicoxenus nitidulus Nyl.) in neuer Beleuchtung. Z. Morph. Okol. Tiere 3, 452-476.

WheELER, W. M. (1904): Three new genera of inquiline ants from Utah and Colorado. Bull. Amer. Mus. Nat. Hist. 20, 1-17, pl. I.

WheELER, W. M. (1910): Ants, their structure, developent and behavior. Columbia Univ. Press, New York and London. 

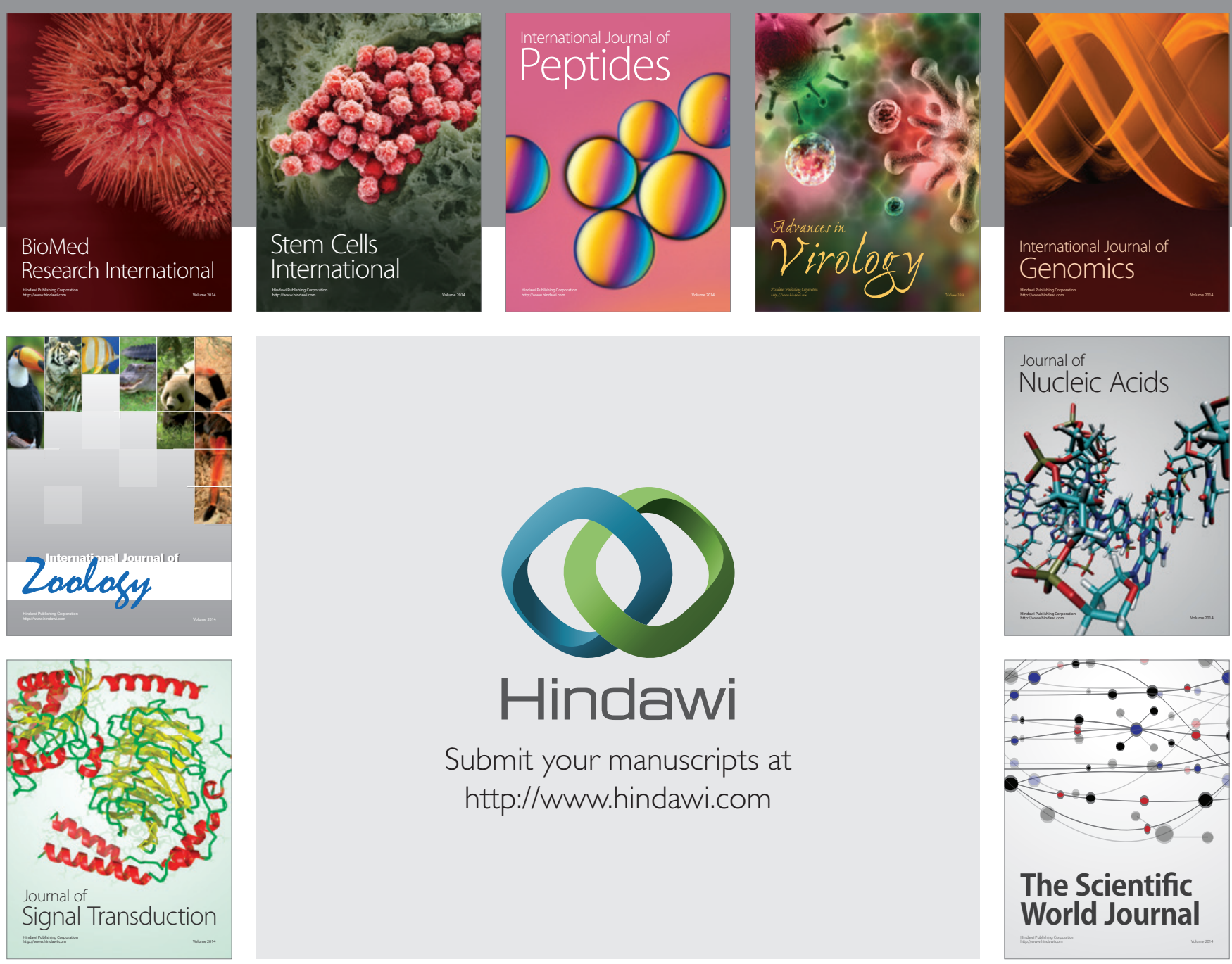

Submit your manuscripts at

http://www.hindawi.com
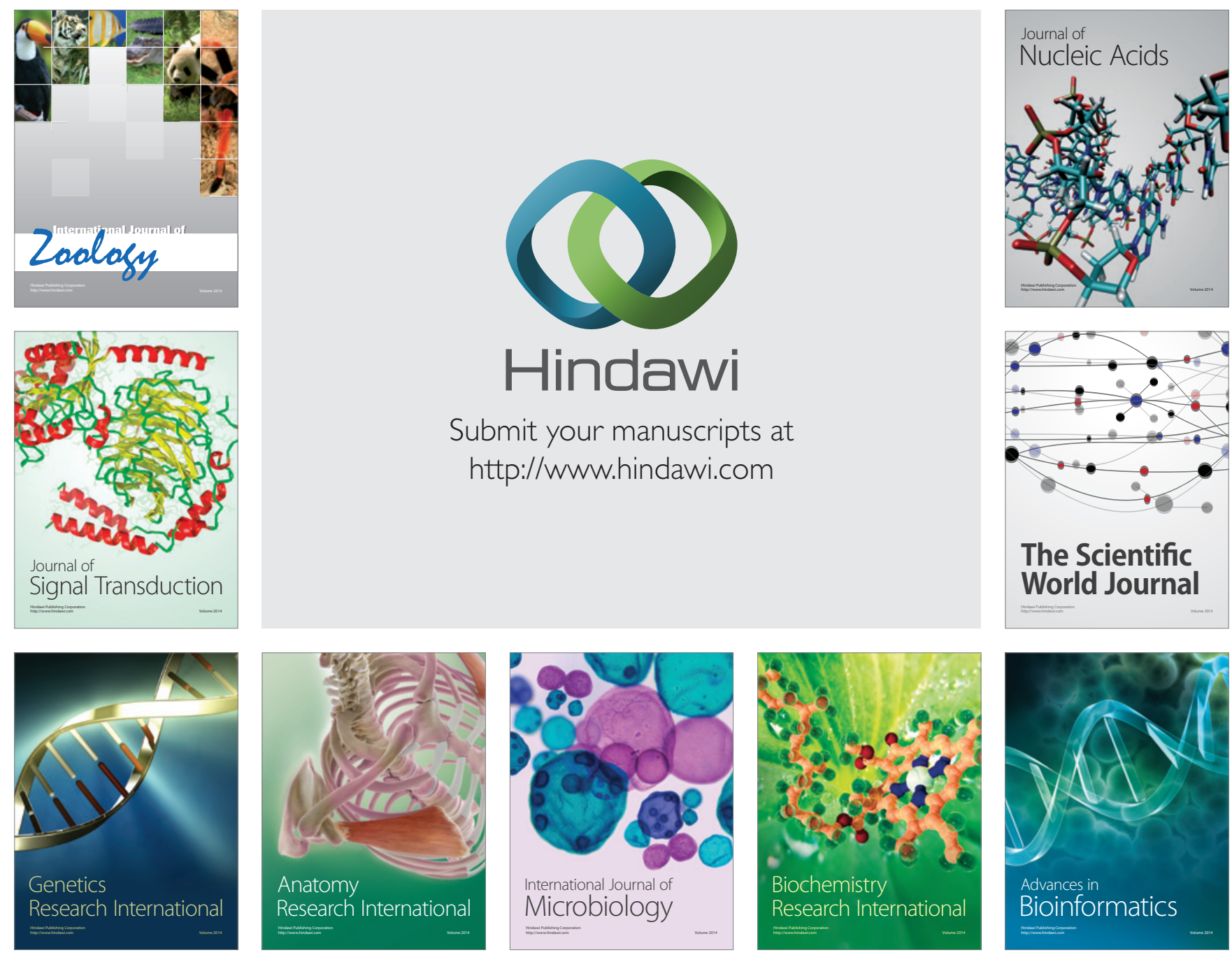

The Scientific World Journal
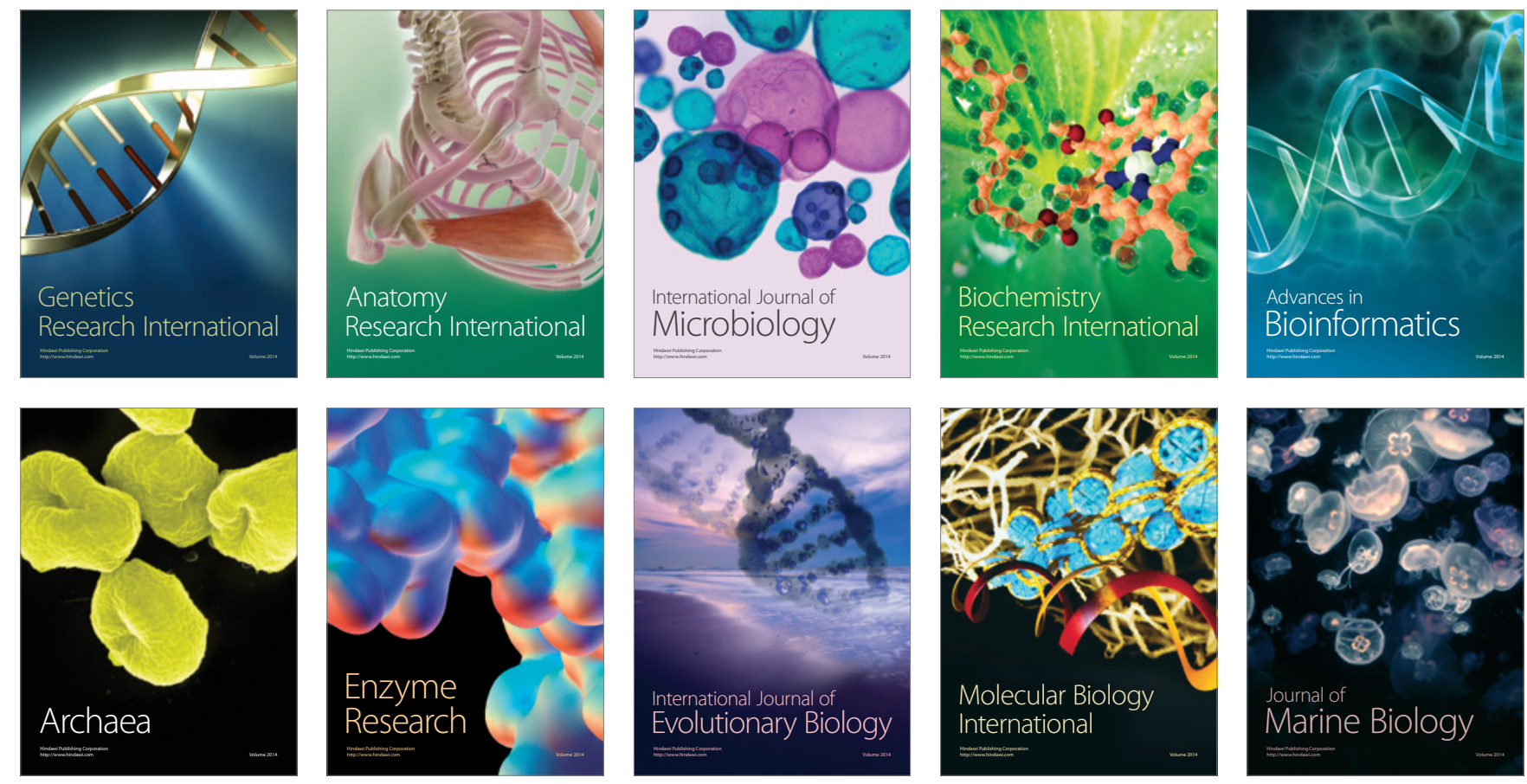